\title{
Range Expansion of Insect Vectors due to Climate Change
}

\author{
Raghuram Koganti and Alan Molumby* \\ ${ }^{1}$ Department of Economics, University of Illinois at Chicago, USA \\ ${ }^{2}$ Department of Biological Sciences, University of Illinois at Chicago, USA
}

*Corresponding author: Alan Molumby, University of Illinois at Chicago, Chicago, IL, USA.

To Cite This Article: Alan Molumby, Range Expansion of Insect Vectors due to Climate Change. Am J Biomed Sci \& Res. 2019 - 6(5). AJBSR. MS.ID.001078. DOI: 10.34297/AJBSR.2019.06.001078.

Received: 畊 November 222019 ; Published: 眥 December 19, 2019

\section{Opinion}

The United Nations Intergovernmental Panel on Climate Change [IPCC] has attributed $1 \mathrm{oC}$ of global warming since the Industrial Revolution to anthropogenic causes, $0.50 \mathrm{C}$ of which occurred since the 1970s. The IPCC also projects that the world is likely to be an additional $1.5 \mathrm{oC}$ hotter in just a few decades given the current rate of greenhouse gas emissions [1]. Above a $20 \mathrm{C}$ increase in mean global temperatures, the results will be catastrophic and likely irreversible [2]. The increase in global temperatures will cause natural disasters to become more frequent and severe, ecosystems to be destroyed, and forever alter the climate of certain regions around the globe [36]. An oft-overlooked consequence of a warmer planet is the range expansion of many insect vectors and, more importantly, their plethora of associated diseases. Many diseases will become more prevalent if global warming continues and breach areas previously considered to be safe from harm. Consider the dramatic effects of increases in the range of the common mosquito, Aedes aegypti, and the Asian tiger mosquito, Aedes albopictus. By the end of this century, almost a billion people will be newly exposed to these mosquitoes and their associated diseases [7].

Europe, eastern Africa, the United States, and Canada will bear the brunt of this increase in mosquito exposure. The Asian tiger mosquito has already been invading into new areas of the USA, with one study finding that the number of trapping sites positive for the A. albopictus in Connecticut increased from just 1 in 2006 to 936 in 2016 [8]. In the northeastern United States, the number of people under threat from A. albopictus has been projected to double by the close of the century [9]. The silver lining of this rise in mosquito populations is that they may decrease in certain parts of Africa, South America, and southeast Asia which currently have a high prevalence of both types of mosquitoes. However, considering the areas which will still suffer from mosquito-borne diseases, an estimated 3.9 billion people in 120 countries are at risk [10]. Now consider the variety of diseases that can be transmitted by these two types of mosquitoes. Malaria outbreaks, responsible for over 435,000 deaths globally in 2017 , are expected to become more prevalent [11]. Models of Zika virus, an arbovirus which causes birth defects and neurological disorders, have predicted its range to shift upwards towards North America [12].

By 2085, over half of the world's population will be at risk for Dengue virus and the debilitating fever associated with it [13]. Likewise, Chikungunya viral infections and severe joint pain will harm Chinese, North American, South American, and European populations that previously enjoyed relatively low rates of the disease [14]. Rift valley fever will spread and plague countries north of the Mediterranean and Middle East [15]. Preventative measures for these diseases are limited. Only dengue virus has an approved vaccine with a high efficacy although preliminary tests of vaccines for other viruses are currently underway $[16,17]$. The other viruses lack vaccines and therefore present severe threats towards newly exposed populations [18,19]. For an appreciation of the scale of this problem, consider that mosquitos are only one of many vectors for disease whose range will expand as a result of global warming. Others include kissing bugs for Chagas disease [20], sand flies for Leishmaniasis [21]. Tsetse flies for sleeping sickness [22], and Ixodes ticks for Lyme disease [23]. Beyond viruses carried by insect vectors, others that are likely to become more prevalent include the rabies virus [24] and arenaviruses which spread Lassa fever [25],

Range expansions for these vectors may not be explosive and garner much media attention. Nonetheless, they pose significant threats to the well-being of many human beings worldwide. Unfortunately, many developing countries are ill-prepared for outbreaks of these vector-borne diseases. Developing countries have mortality rates from vector-borne diseases that are 300 times greater than those from developed countries [26]. The death toll 
from the developing world alone would be substantial if the range of insect vectors expands at the current rate. Even in the developed world, public health systems may struggle in the face of new threats to populations. These studies suggest that drastic action must be taken immediately to mitigate the spread of these diseases. Global CO2 emissions must be reduced as quickly as possible through a variety of mechanisms: carbon pricing, investment into cleaner energy and carbon sequestration, moving towards plant-based eating, and sustainable development. Significant research funding must be devoted to developing vaccines and new treatments, especially for populations that will be newly exposed to these diseases.

On a smaller scale, individuals can voice their concerns to their local representatives and pressure them to sponsor greener policies. The facts of the matter are that the world is warming due to anthropogenic causes, and a warmer world will make its people susceptible to serious diseases, many of them transmitted by expanding insect vectors. It is up to us to realize the severity of the problem and take action.

\section{References}

1. IPCC (2015) Global Warming of $1.5^{\circ} \mathrm{C}$.

2. McGushin AY, Tcholakov, S Hajat (2018) Climate Change and Human Health: Health Impacts of Warming of $1.5^{\circ} \mathrm{C}$ and $2{ }^{\circ} \mathrm{C}$. Int J Environ Res Public Health 15(6).

3. Berry P, PM Enright, J Shumake-Guillemot, E Villalobos Prats, D. Campbell-Lendrum (2018) Assessing Health Vulnerabilities and Adaptation to Climate Change: A Review of International Progress. Int J Environ Res Public Health 15(12).

4. Alhassan S, WL Hadwen (2017) Challenges and Opportunities for Mainstreaming Climate Change Adaptation into WaSH Development Planning in Ghana. Int J Environ Res Public Health 14(7).

5. Filho WL, AQ Al-Amin, GJ Nagy, UM Azeiteiro, L Wiesböck, et al. (2018) A Comparative Analysis of Climate-Risk and Extreme Event-Related Impacts on Well-Being and Health: Policy Implications. Int J Environ Res Public Health 15(2).

6. Sauerborn R, K Ebi (2012) Climate change and natural disasters integrating science and practice to protect health. Global Health Action 5: 1-7.

7. Ryan SJ, CJ Carlson, EA Mordecai, LR Johnson (2019) Global expansion and redistribution of Aedes-borne virus transmission risk with climate change. PLoS Neglected Tropical Diseases 13(3).

8. Armstrong PM, TG Andreadis, J J Shepard, MC Thomas (2017) Northern range expansion of the Asian tiger mosquito (Aedes albopictus): Analysis of mosquito data from Connecticut, USA. PLoS Neglected Tropical Diseases 11(5).

9. Rochlin I, DV Ninivaggi, ML Hutchinson, A Farajollahi (2013) Climate Change and Range Expansion of the Asian Tiger Mosquito (Aedes albopictus) in Northeastern USA: Implications for Public Health Practitioners. PloS One 8(4).
10. Brady OJ, PW Gething, S Bhatt, JP Messina, J S Brownstein, et al. (2012) Refining the Global Spatial Limits of Dengue Virus Transmission by Evidence-Based Consensus. PLoS Neglected Tropical Diseases 6(8).

11. Caminade C, S Kovats, J Rocklov, AM Tompkins, AP Morse, et al. (2014) Impact of climate change on global malaria distribution. Proc Natl Acad Sci U S A 111: 3286-3291.

12. Tesla B, LR Demakovsky, EA Mordecai, SJ Ryan, MH Bonds, et al. (2018) Temperature drives Zika virus transmission: Evidence from empirical and mathematical models. Proceedings of the Royal Society B: Biological Sciences pp. 285.

13. Hales S, N de Wet, J Maindonald, A Woodward (2002) Potential effect of population and climate changes on global distribution of dengue fever: an empirical model. Lancet 360: 830-834.

14. Tjaden NB, JE Suk, D Fischer, SM Thomas, C Beierkuhnlein, et al. (2017) Modelling the effects of global climate change on Chikungunya transmission in the 21st century. Scientific Reports 7: 1-11.

15. Martin V, V Chevalier, P Ceccato, A Anyamba, L De Simone, et al. (2008) The impact of climate change on the epidemiology and control of Rift Valley fever. Rev. Off Int Epizoot 27: 413-426.

16. Scott LJ (2016) Tetravalent Dengue Vaccine: A Review in the Prevention of Dengue Disease. Drugs 76(13): 1301-1312.

17. Anonymous WHO (2019) Q\&A on the malaria vaccine implementation programme (MVIP).

18. Faburay B, AD LaBeaud, DS McVey, WC Wilson, JA Richt (2017) Current Status of Rift Valley Fever Vaccine Development. Vaccines (Basel) 5(3).

19. Krauer F, M Riesen, L Reveiz, OT Oladapo R. Martínez-Vega, et al. (2017) Zika Virus Infection as a Cause of Congenital Brain Abnormalities and Guillain-Barré Syndrome: Systematic Review. PLoS Med 14(1).

20. Stephen A. Klotz, Patricia L Dorn, Mark Mosbacher, Justin O Schmidt (2014) Kissing Bugs in the United States: Risk for Vector-Borne Disease in Humans. Environmental Health Insights p. 49-59.

21. González C, O Wang, SE Strutz, C González-Salazar, V Sánchez-Cordero, et al. (2010) Climate Change and Risk of Leishmaniasis in North America: Predictions from Ecological Niche Models of Vector and Reservoir Species. PLoS Neglected Tropical Diseases 4(1).

22. Moore S, S Shrestha, KW Tomlinson, H Vuong (2012) Predicting the effect of climate change on African trypanosomiasis: integrating epidemiology with parasite and vector biology. Journal of the Royal Society Interface 9: 817-830.

23. Medlock JM, KM Hansford, A Bormane, M Derdakova, A Estrada-Peña, et al. (2013) Driving forces for changes in geographical distribution of Ixodes ricinus ticks in Europe. Parasit Vectors 6: 1.

24. Hayes MA, AJ Piaggio (2018) Assessing the potential impacts of a changing climate on the distribution of a rabies virus vector. Plos One 13: e0192887.

25. Tambo E, OT Adetunde, OA Olalubi (2018) Re-emerging Lassa fever outbreaks in Nigeria: Re-enforcing "One Health" community surveillance and emergency response practice. Infect Dis Poverty 7(1).

26. Campbell-Lendrum D, L Manga, M Bagayoko, J Sommerfeld (2015) Climate change and vector-borne diseases: what are the implications for public health research and policy? Philos Trans R Soc Lond B Biol Sci 370. 